\title{
Construction of SET overexpression vector and its effects on the proliferation and apoptosis of 293T cells
}

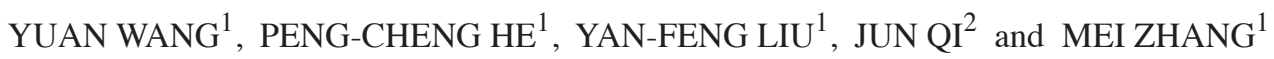 \\ ${ }^{1}$ Department of Hematology, The First Affiliated Hospital of Xi'an Jiaotong University, Medical College, Xi'an, Shaanxi 710061; \\ ${ }^{2}$ Institute of Xi'an Blood Bank, Shaanxi Blood Center, Xi'an, Shaanxi 710068, P.R. China
}

Received March 18, 2015; Accepted March 8, 2016

DOI: $10.3892 / \mathrm{mmr} .2016 .5049$

\begin{abstract}
The expression of SET nuclear proto-oncogene (SET) is commonly associated with cell proliferation and tumorigenesis. In the present study, a eukaryotic SET expression plasmid (pEGFP-N1-SET) was constructed and transiently transfected into 293T human embryonic kidney cells. Transfection led to expression of the SET oncoprotein at high levels, as indicated by polymerase chain reaction and western blot analysis. In addition, the relative mRNA and protein expression of protein phosphatase 2A in pEGFP-N1-SET-transfected 293T cells was downregulated compared with that in empty vector-transfected cells. Furthermore, overexpression of SET increased the percentage of $293 \mathrm{~T}$ cells in $\mathrm{S}$ and $\mathrm{G}_{2} / \mathrm{M}$ phases compared with the control transfectants. An increase in B-cell lymphoma 2 (Bcl-2) and a decrease in Bcl-2-associated X (Bax) protein expression was observed in the pEGFP-N1-SET-transfected cells compared with that in the controls, and their susceptibility to $\mathrm{As}_{4} \mathrm{~S}_{4}$-induced apoptosis was decreased. The protein SET is involved in a number of cellular processes, including DNA replication, chromatin remodeling, gene transcription, differentiation, migration and cell cycle regulation. SET is overexpressed in several neoplasms, particularly in acute myeloid leukemia. The findings of the present study suggested that the SET gene may contribute to tumorigenesis and may be a potential novel effective therapeutic target for leukemia and other cancer types.
\end{abstract}

\section{Introduction}

SET nuclear proto-oncogene (SET), also known as protein phosphatase type $2 \mathrm{~A}$ inhibitor (I2PP2A) or template-activating

Correspondence to: Professor Mei Zhang or Mr. Peng-Cheng He, Department of Hematology, The First Affiliated Hospital of Xi'an Jiaotong University, Medical College, 277 Yanta West Road, Xi'an, Shaanxi 710061, P.R. China

E-mail: meizhang_med@163.com

E-mail: hepc@163.com

Key words: transfection, SET, protein phosphatase 2A, cell cycle, tetraarsenic tetrasulfide, apoptosis factor- $1 \beta$, is involved in a number of cell processes, including the replication of DNA, chromatin remodeling, gene transcription, differentiation, migration and cell cycle regulation (1). The SET protein was initially extracted from the bone marrow of a leukemia patient (2). Originally identified as a potent PP2A inhibitor, SET is overexpressed in several neoplasms $(3,4)$, particularly acute myeloid leukemia (5). N-terminal and internal amino acid sequencing indicated that I2PP2A was a truncated form of SET (5) Clinical data have indicated that patients with SET overexpression exhibit worse overall survival and event-free survival, suggesting an oncogenic role of SET in tumorigenesis (1).

In our previous proteomics study, the ATRA-resistant acute promyelocytic leukemia (APL) NB4-R1 cell line was treated with $25 \mu \mathrm{mol} / 1 \mathrm{As}_{4} \mathrm{~S}_{4}$ and an $\mathrm{As}_{4} \mathrm{~S}_{4}$-induced differential protein expression profile was obtained (6). There was a significant decrease in the expression of the SET oncoprotein after the treatment with $\mathrm{As}_{4} \mathrm{~S}_{4}$ for $24 \mathrm{~h}$, which was completely abolished after treatment for $48 \mathrm{~h}$ compared with the vector control; this indicated the importance of SET in the regulation of signal transduction pathways and in the mechanism of APL cell apoptosis. Next, we further investigated the possible cellular and molecular mechanisms of $\mathrm{As}_{4} \mathrm{~S}_{4}$ treatment and the role of SET in the apoptosis of NB4-R1 cells. Consistent with previous studies, it was found that $\mathrm{As}_{4} \mathrm{~S}_{4}$-induced apoptosis was accompanied by reduced mRNA and protein expression levels of SET in the NB4-R1 cells (Wang et al, unpublished data). These results indicated that $\mathrm{As}_{4} \mathrm{~S}_{4}$ may induce the apoptosis of NB4-R1 cells through the downregulation of SET protein expression.

In the present study the SET gene was selected for further investigation. To avoid interference and possible compensation by other genes, SET was transfected into human embryonic kidney $293 \mathrm{~T}$ cells and it was observed whether SET expression led to a change in the expression of PP2A or the apoptosis-related genes Bcl-2 and Bax in 293T cells treated with $\mathrm{As}_{4} \mathrm{~S}_{4}$.

\section{Materials and methods}

Cell culture and reagents. The human embryonic kidney 293T cell line and the APL NB4-R1 cell line were stored in in the Oncology Research Laboratory, The First Affiiated Hospital of Xi'an Jiaotong University (Xi'an, China). The 293T cells were 
maintained in Dulbecco's modified Eagle's medium (Gibco; Thermo Fisher Scientific Inc., Waltham, MA, USA) at $37^{\circ} \mathrm{C}$ in a $5 \% \mathrm{CO}_{2}$ atmosphere in air. The growth medium was supplemented with $10 \%$ heat-inactivated (at $56^{\circ} \mathrm{C}$ for $30 \mathrm{~min}$ ) fetal bovine serum (FBS), penicillin $(100 \mathrm{U} / \mathrm{ml})$ and streptomycin $(100 \mu \mathrm{g} / \mathrm{ml})$. The NB4-R1 cells were cultured in RPMI-1640 medium (Gibco; Thermo Fisher Scientific Inc.) supplemented with $10 \% \mathrm{FBS}, 100 \mathrm{U} / \mathrm{ml}$ penicillin and $100 \mu \mathrm{g} / \mathrm{ml}$ streptomycin, and maintained in a $5 \% \mathrm{CO}_{2}$ humidified atmosphere at $37^{\circ} \mathrm{C}$.

Extraction of total RNA and reverse transcription-polymerase chain reaction ( $R T-P C R)$. The total RNA was extracted from the NB4-R1 cells using TRIzol reagent (Invitrogen; Thermo Fisher Scientific Inc.) and was precisely quantified using an ultraviolet spectrophotometer. The sequences of the primers for SET amplification are listed below: Forward, 5'-CCGCTCGAGATGTCGGCGCCGGCG GCCAAAG-3' (the underlined section represents the XhoI cleavage site); and reverse, 5'-GGGGTACCGTGTCATCTT CTCCTTCATCC-3' (the underlined section indicates the $K p n$ I cleavage site). The RT reaction system included $2 \mu \mathrm{g}$ RNA, $2 \mu 1$ 5X PrimeScript RT Master Mix (Takara Bio Inc., Otsu, Japan) and RNase-free $\mathrm{dH}_{2} \mathrm{O}$ to a final volume of $10 \mu \mathrm{l}$. The reaction program was as follows: $37^{\circ} \mathrm{C}$ for $15 \mathrm{~min}$, followed by $85^{\circ} \mathrm{C}$ for $5 \mathrm{sec}$. The PCR was performed in a total volume of $20 \mu \mathrm{l}$, which included $1 \mu \mathrm{l}(10 \mathrm{ng} / \mu \mathrm{l}) \mathrm{cDNA}$, $4 \mu \mathrm{l} 5 \mathrm{X}$ Taq buffer; $1.6 \mu \mathrm{l}(2.5 \mathrm{mM}) \mathrm{dNTPs}, 0.4 \mu \mathrm{l}(10 \mu \mathrm{M})$ forward and reverse primer; $0.2 \mu 1$ Taq polymerase; and $12.4 \mu \mathrm{lddH_{2 }}$ O. The reaction program was performed in a PCR Thermocycle Instrument (Bio-Rad Laboratories, Inc., Hercules, CA, USA) as follows: $94^{\circ} \mathrm{C}$ for $5 \mathrm{~min}$, and then 30 cycles of $94^{\circ} \mathrm{C}$ for $30 \mathrm{sec}, 55^{\circ} \mathrm{C}$ for $30 \mathrm{sec}, 72^{\circ} \mathrm{C}$ for $50 \mathrm{sec}$ and an extension step of $72^{\circ} \mathrm{C}$ for $10 \mathrm{~min}$. The amplified PCR products were electrophoresed on a $1 \%$ agarose gel (Beijing SBS Genetech Co., Ltd., Beijing, China) and were visualized under ultraviolet light using a Chemidox XRS and Quantity One gel image analysis system (Bio-Rad Laboratories, Inc.). The length of the amplified PCR segment was $850 \mathrm{bp}$ and the experiment was replicated 3 times.

Construction of pEGFP-N1-SET plasmid. The gel-purified PCR segment was cut with $X h o \mathrm{I}$ and $K p n \mathrm{I}$ restriction enzymes. The length of the restriction enzyme digestion product was $835 \mathrm{bp}$. Next, the segment was introduced into the pEGFP-N1 plasmid (Shanghai Genechem Co., Ltd., Shanghai, China). The pEGFP-N1-SET construct was transformed into DH5 $\alpha$ cells (stored in our laboratory), and then the correct fragment was identified as a mini-plasmid by digestion with $\mathrm{XhoI}$ and $K p n \mathrm{I}$, and was verified as the correct clone through sequence analysis.

Transfection of 2937 cells. For transient transfection, the 293T cells were plated at a density of $8 \times 10^{4} / \mathrm{ml}$ cells per well in 6-well plates and transfected with $2 \mu \mathrm{g}$ pEGFP-N1-SET or pEGFP-N1 (vector group) plasmids using Lipofectamine 2000 reagent (Invitrogen; Thermo Fisher Scientific Inc.). After $48 \mathrm{~h}$ of transfection, the cells were observed with an inverted fluorescence microscope (Olympus Corporation, Tokyo, Japan) and used for further assays.
SET and PP2A $m R N A$ analyses. The total RNA was extracted from each sample of 293T cells in TRIzol reagent. Each RNA sample $(1 \mu \mathrm{g})$ was reverse-transcribed into cDNA using a RevertAid First Strand cDNA Synthesis kit (Thermo Fisher Scientific Inc.) according to the manufacturer's protocols, and then the cDNA was used for RT-quantitative PCR (RT-qPCR). The RT-qPCR amplification reaction contained $12.5 \mu \mathrm{l}$ 2X SYBR-Green I, $1 \mu \mathrm{l}$ forward $(0.4 \mu \mathrm{M})$ and $1 \mu \mathrm{l}$ reverse $(0.4 \mu \mathrm{M})$ primer and $10.5 \mu \mathrm{l}$ cDNA diluted with RNase-free water. The RT-qPCR included control samples with RNase-free water instead of the cDNA template. All samples were analyzed in three independent biological replicates. The PCR conditions were as follows: Initial denaturation at $95^{\circ} \mathrm{C}$ for $30 \mathrm{sec}$, denaturing at $95^{\circ} \mathrm{C}$ for $5 \mathrm{sec}$, and annealing at $60^{\circ} \mathrm{C}$ for $30 \mathrm{sec}$, where the last two steps of the reaction were repeated for 40 cycles. The primer sequences used to amplify the target genes are listed as follows: SET forward, 5'-CAT CTTCGAAGTCCACCGAAATC-3' and reverse; 5'-TGCATC AGAATGGTCAGTAAACCAG-3'; PP2A forward, 5'-GTA ACCAAGCTGCAATCATGGAA-3' and reverse, 5'-CTCTAC GAGGTGCTGGGTCAAAC-3'; and glyceraldehyde 3-phosphate dehydrogenase (GAPDH) forward, 5'-CACCCTGTT GCTGTAGCCAAA-3' and reverse, 5'-CACCCTGTTGCT GTAGCCAAA-3'. RT-qPCR was conducted using an iCycler iQ Real-Time PCR Detection system (Bio-Rad Laboratories Inc.) with SYBR-Green I fluorescent dye (Takara Bio Inc.). The relative mRNA levels of the target genes were expressed in terms of the rates that were based on the cycle threshold (Cq) (7). The mRNA expression levels of each group were compared through $2^{-\Delta \Delta C q}$. The GAPDH gene was used for inter-sample normalization and three independent experiments were performed in triplicate.

SET and PP2A protein analysis. The cultured cells were harvested and washed three times with cold phosphate-buffered saline (PBS). Next, the cells were solubilized in radioimmunoprecipitation assay buffer containing a protease inhibitor cocktail containing $104 \mathrm{mM}$ AEBSF, $80 \mu \mathrm{M}$ aprotinin, $4 \mathrm{mM}$ bestatin, $1.4 \mathrm{mM}$ E-64, $2 \mathrm{mM}$ leupeptin and $1.5 \mathrm{mM}$ pepstatin A (Sigma-Aldrich, St. Louis, MO, USA). Subsequent to being maintained on ice for $10 \mathrm{~min}$, the cell suspension was centrifuged for protein at $15,500 \mathrm{xg}$ for $15 \mathrm{~min}$ at $4^{\circ} \mathrm{C}$. The protein $(30 \mu \mathrm{g})$ was separated on $10 \%$ sodium dodecyl sulfate polyacrylamide gel electrophoresis gels and transferred to a nitrocellulose membrane at $110 \mathrm{~V}$ for $2 \mathrm{~h}$. The non-specific binding sites on the membranes were blocked with 5\% (w/v) skimmed milk in Tris-buffered saline [TBS: $20 \mathrm{mM}$ Tris- $\mathrm{HCl}$ and $200 \mathrm{mM} \mathrm{NaCl}$ ( $\mathrm{pH}$ 7.6)] for $2 \mathrm{~h}$ under gentle rocking at room temperature. Next, the membranes were incubated with the following primary antibodies: Rabbit polyclonal anti-SET antibody (cat. no. ab92872) and rabbit monoclonal anti-PP2A (cat. no. ab32141) antibodies (1:10,000; Abcam, Cambridge, MA, USA); and mouse monoclonal anti-GAPDH antibody (1:10,000; cat. no. sc-47724; Santa Cruz Biotechnology Inc., Dallas, TX, USA) directed against the protein or enzyme of interest for $1 \mathrm{~h}$ at room temperature and then at $4^{\circ} \mathrm{C}$ overnight. The membranes were then incubated with goat anti-rabbit (cat. no. sc-2004) or goat anti-mouse (cat. no. sc-2005) horseradish peroxidase-conjugated secondary antibody (Santa Cruz Biotechnology, Inc.) for $1 \mathrm{~h}$ at room temperature. Subsequent to being washed extensively with TBS 
plus Tween 20, the membranes were incubated under chemiluminescence and wrapped in clear plastic wrap for film exposure. The bands on the immunoblots were quantified using Quantity One version 4.6.2 software (Bio-Rad Laboratories Inc.). The protein expression of each sample was internally normalized to GAPDH, and the quantity was compared with the expression of the transfected control groups.

Cell cycle analysis. The cell cycle distribution was analyzed via flow cytometry (Becton Dickinson FACSCalibur double laser flow cytometer; BD Biosciences, Franklin Lakes, NJ, USA). The $293 \mathrm{~T}$ cells $\left(1 \times 10^{6} / \mathrm{ml}\right)$ were harvested and washed twice with ice-cold PBS. The cells were suspended gently in $70 \%$ chilled ethanol at $-20^{\circ} \mathrm{C}$ overnight. After washing with PBS, the cells were re-suspended in $500 \mu \mathrm{l}$ of PBS containing propidium iodide $(50 \mu \mathrm{g} / \mathrm{ml})$ and RNase $(50 \mu \mathrm{g} / \mathrm{ml})$, and incubated for $30 \mathrm{~min}$ at $37^{\circ} \mathrm{C}$ in the dark. The cell cycle phase distribution of each experiment was analyzed using 10,000 cells per sample. The proportion of cells in the $G_{0} / G_{1}$, $\mathrm{S}$ and $\mathrm{G}_{2} / \mathrm{M}$ phases were represented as DNA histograms.

Bcl-2 and Bax protein analyses. At $48 \mathrm{~h}$ post-transfection, the transfected cell medium was changed to new medium that contained $5 \mu \mathrm{mol} / \mathrm{l} \mathrm{As}_{4} \mathrm{~S}_{4}$ for $24 \mathrm{~h}$. The method was similar to that used for western blotting analysis. The relevant primary antibodies were mouse monoclonal anti-Bcl-2 (cat. no. sc-7382) or rabbit polyclonal anti-Bax (cat. no. sc-493) antibodies (1:1,000 dilutions; Santa Cruz Biotechnology Inc.). The protein expression of each sample was internally normalized to GAPDH.

Statistical analysis. Experiments were performed in duplicates or triplicates over three or more independent experiments and the results are presented as the mean \pm standard deviation. Statistical significance was calculated via a t-test using SPSS software, version 19.0 (IBM SPSS, Armonk, NY, USA). P<0.05 was used to indicate a statistically significant difference.

\section{Results}

Construction and package of plasmid. Using PCR-based techniques, an 850-bp human SET gene product of the correct size was generated, and then the gel-purified PCR segment was cut with the XhoI and KpnI restriction enzymes. The length of the restriction enzyme digestion product was $835 \mathrm{bp}$. Next, the segment was inserted into the pEGFP-N1 expression vector.

The SET gene product and the positive recombinant clones were identified with PCR (Fig. 1). DNA sequencing analysis confirmed that the sequences were correct.

SET expression analysis. As the recombinant plasmid pEGFP-N1-SET was labeled with enhanced green florescent protein (EGFP), EGFP expression could be observed by laser confocal microscopy, indirectly reflecting the transfection rate of the SET gene. At $48 \mathrm{~h}$ post-transfection, the pEGFP-N1 empty vector and pEGFP-N1-SET construct transfection yielded efficiencies of $>90 \%$, as visualized by fluorescence microscopy for EGFP expression (Fig. 2).

To confirm that the gene had been transfected into the cells, RT-qPCR and western blotting was used to detect SET expression in the recombinant cells. The results showed that the SET
A
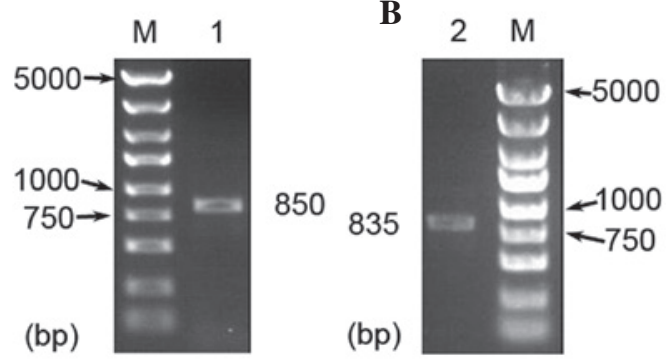

C

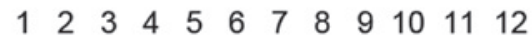

(bp)

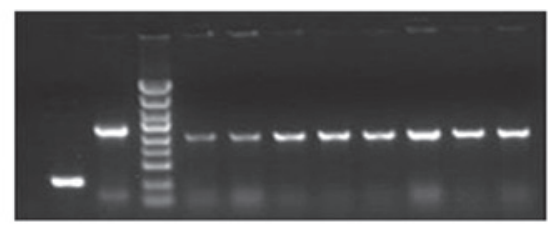

1115

Figure 1. Gels showing products of (A) PCR and (B) restriction enzyme analysis. Lanes: M, DNA marker (5,000, 3,000, 2,000, 1,500, 1,000, 750, 500, 250 and $100 \mathrm{bp}$ ); 1, PCR-amplified SET gene; 2, PCR-amplified product of double-digestion by XhoI and KpnI. (C) Gel electrophoretic analysis of vectors. Lanes: 1 , double-distilled $\mathrm{H}_{2} \mathrm{O} ; 2$, recombinant negative vector pEGFP-N1; 3, GAPDH; 4, DNA marker (as above); 5-12, recombinant positive vector of pEGFP-N1-SET. PCR, polymerase chain reaction; EGFP, enhanced green fluorescent protein; GAPDH, glyceraldehyde 3-phosphate dehydrogenase.
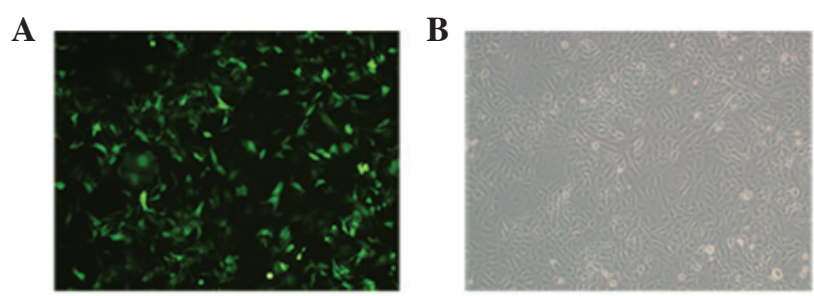

C

D
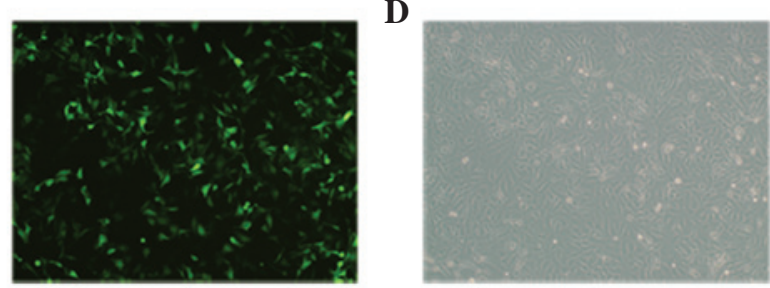

Figure 2. Analysis of $293 \mathrm{~T}$ cells by inverted phase-contrast microscopy and fluorescence microscopy (magnification, x200). (A) Fluorescence and (B) light microscopy images of 293T cells transfected with pEGFP-N1 plasmid; and (C) fluorescence and (D) light microscopy images of $293 \mathrm{~T}$ cells transfected with pEGFP-N1-SET plasmid. EGFP, enhanced green fluorescent protein.

expression of the construct transfection group was markedly increased at the mRNA and protein levels compared with that of the empty vector group. Both real-time quantitative PCR $(\mathrm{P}=2.1 \times 10-7)$ and western blotting $(\mathrm{P}=0.001)$ demonstrated that pEGFP-N1-SET were effective for SET overexpression. These results demonstrated that the target gene had been successfully transfected (Fig. 3).

PP2A expression analyses. PP2A expression was detected by RT-qPCR and western blotting to ascertain if the PP2A gene was involved in the study. PP2A expression was decreased by 92\% (mRNA; $\mathrm{P}=0.0002$ ) and $\sim 47 \%$ (protein; $\mathrm{P}=0.002$ ) in 

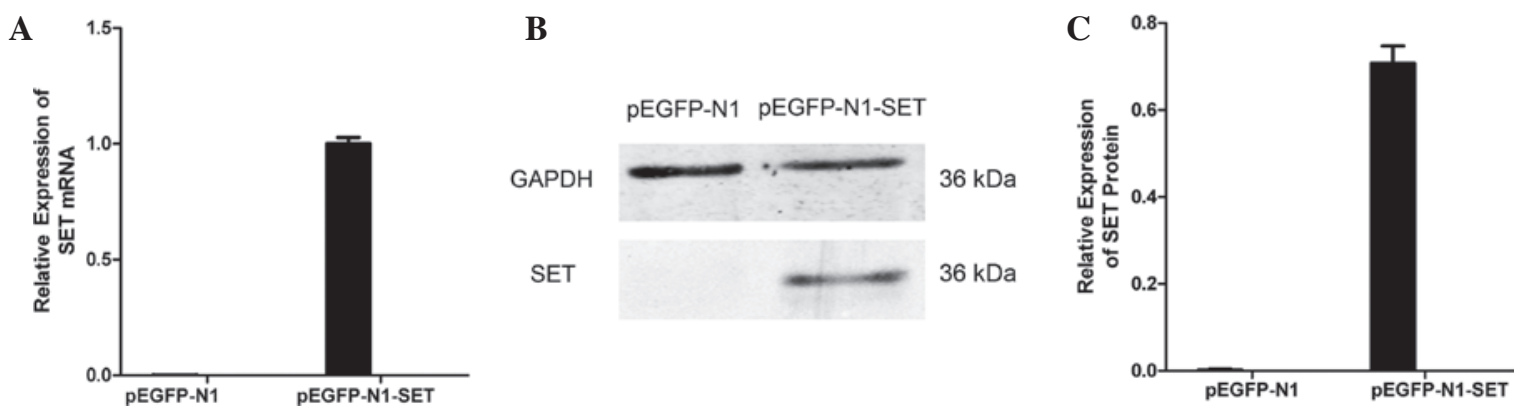

Figure 3. Vector-mediated SET expression in 293T cells. (A) mRNA expression of SET was detected by reverse transcription-quantitative polymerase chain reaction analysis. (B) Representative western blot for the detection of the protein expression of SET. GAPDH expression was used as a loading control. (C) Relative expression of SET protein as determined by densitometric analysis of protein bands. Values are expressed as the mean \pm standard deviation from three individual experiments. GAPDH, glyceraldehyde-3-phosphate dehydrogenase; EGFP, enhanced green fluorescent protein.
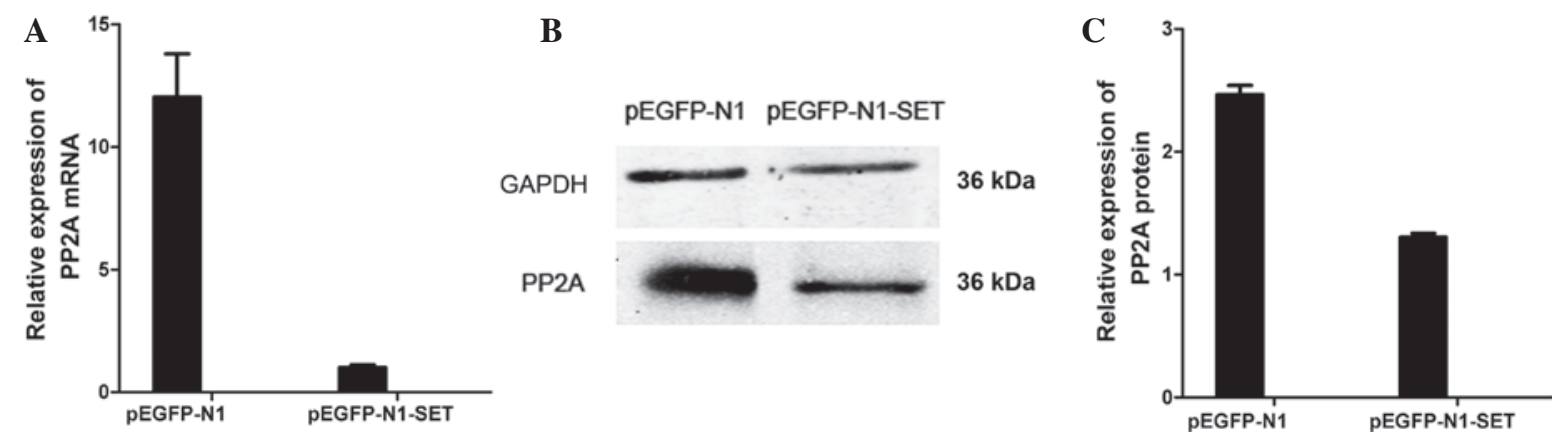

Figure 4. PP2A is expressed in 293T cells following upregulation of SET. (A) mRNA expression of PP2A was detected by reverse transcription-quantitative polymerase chain reaction analysis. (B) Representative western blot for the detection of the protein expression of PP2A. GAPDH expression was used as loading control. (C) Relative expression of PP2A protein as determined by densitometric analysis of protein bands. Values are expressed as the mean \pm standard deviation from three individual experiments. GAPDH, glyceraldehyde-3-phosphate dehydrogenase; EGFP, enhanced green fluorescent protein; PP2A, protein phosphatase $2 \mathrm{~A}$.

the pEGFP-N1-SET-transfected 293T cells compared with the pEGFP-N1-transfected control group (Fig. 4).

SET increases the percentage of transfected cells in $S$ and $G_{2} / M$ phases. To monitor the stimulatory effect of SET on cell growth, the effect of SET overexpression on cell cycle progression was investigated by flow cytometric analysis. The result demonstrated that the overexpression of SET significantly increased the cell percentage in the $\mathrm{S}(\mathrm{P}=0.025)$ and $\mathrm{G}_{2} / \mathrm{M}$ $(\mathrm{P}=0.045)$ phases in the 293T cells compared with that in the control transfectants (Fig. 5).

Bcl-2 and Bax expression analyses. Anti-apoptotic Bcl-2 expression and pro-apoptotic Bax expression was detected by western blotting to ascertain if Bcl-2 and Bax were involved in the apoptosis in this study. Bcl-2 expression was increased by $~ 84 \%(\mathrm{P}=0.001)$ in the pEGFP-N1-SET-transfected 293T cells compared with the pEGFP-N1-transfected control group. The incubation with $5 \mu \mathrm{mol} / 1 \mathrm{As}_{4} \mathrm{~S}_{4}$ for $24 \mathrm{~h}$ decreased the relative $\mathrm{Bcl}-2$ expression level by $86 \%(\mathrm{P}=0.001)$ in the pEGFP-N1-transfected 293T cells and by $91 \%(\mathrm{P}=0.001)$ in the pEGFP-N1-SET-transfected cells, when compared with the untreated control cells (Fig. 6).

Bax expression was decreased significantly by $\sim 54 \%$ $(\mathrm{P}=0.004)$ in the pEGFP-N1-SET-transfected group compared with the pEGFP-N1-transfected control group. $\mathrm{As}_{4} \mathrm{~S}_{4}$-treatment increased Bax expression by $14 \%(\mathrm{P}>0.05)$

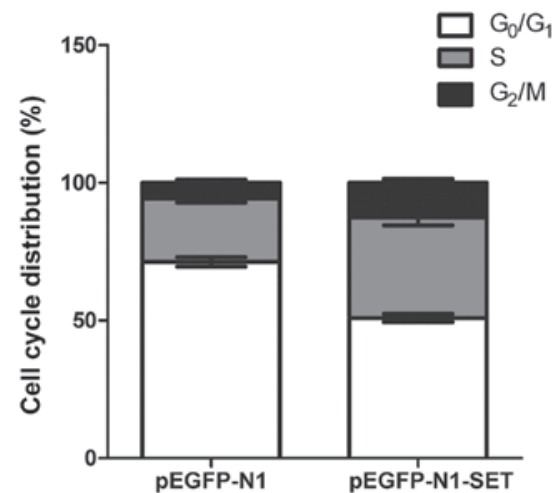

Figure 5. Cell cycle analysis by flow cytometry. Overexpression of SET increased the percentage of 293T cells compared with the control transfectants in the $\mathrm{S}$ phase (36.6 vs. $23.0 \%$, respectively) and $\mathrm{G}_{2} / \mathrm{M}$ phase (12.5 vs. $5.7 \%$, respectively) $(\mathrm{P}<0.05)$. Values are expressed as the mean \pm standard deviation from three individual experiments. EGFP, enhanced green fluorescence protein.

in the pEGFP-N1-transfected cells. In comparison, $\mathrm{As}_{4} \mathrm{~S}_{4}$ addition increased $\mathrm{Bax}$ expression by $66 \%(\mathrm{P}=0.009)$ in the pEGFP-N1-SET-transfected cells (Fig. 6).

\section{Discussion}

Abnormally expressed genes associated with signal transduction play a role in the development of carcinoma. The 
A

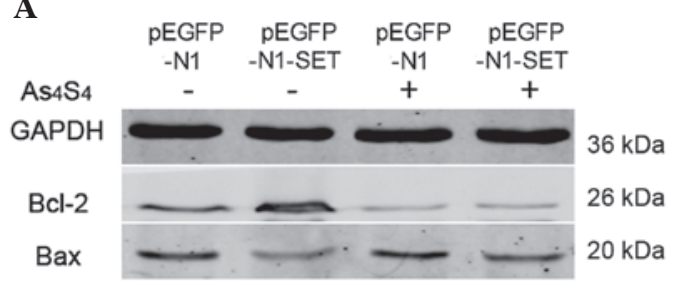

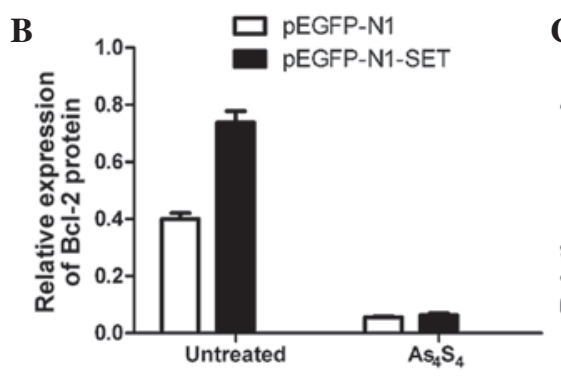

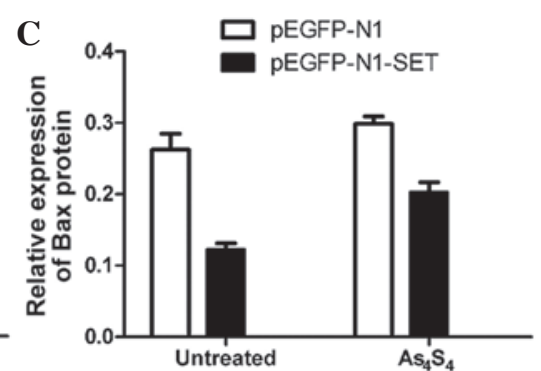

Figure 6. $\mathrm{As}_{4} \mathrm{~S}_{4}$-induced Bcl-2 or Bax protein expression was detected in 293T cells transfected with pEGFP-N1 or pEGFP-N1-SET. Cells in the As $\mathrm{S}_{4}$ groups were treated with $5 \mu \mathrm{mol} / 1 \mathrm{As}_{4} \mathrm{~S}_{4}$ for $24 \mathrm{~h}$. (A) Representative western blots showing Bcl-2 or Bax protein levels. GAPDH was used as the loading control. (B and C) Relative protein levels of Bcl-2 or Bax were determined by densitometric analysis of protein bands. Values are expressed as the mean \pm standard deviation from three individual experiments. GAPDH, glyceraldehyde-3-phosphate dehydrogenase; EGFP, enhanced green fluorescent protein; Bcl-2, B-cell lymphoma 2; Bax, Bcl-2-associated X protein.

investigation of the abnormal expression of genes in cancer can not only enhance our understanding of the pathogenesis of the tumor, but can also provide reliable therapeutic targets. Our previous proteomics study showed a total of 21 proteins that were differentially regulated after treatment with $\mathrm{As}_{4} \mathrm{~S}_{4}$ in NB4-R1 cells, including 5 downregulated proteins and 16 upregulated proteins (6). It was suggested that either the loss of tumor suppressor genes or oncogene overexpression would be involved in the neoplastic cell transcription of normal cells. Among these differential displayed proteins, the expression of the SET oncoprotein showed a significant decrease after the treatment with $\mathrm{As}_{4} \mathrm{~S}_{4}$, which indicated the importance of SET in the regulation of signal transduction pathways (6).

SET oncoprotein expression is often associated with cell proliferation and tumorigenesis $(8,9)$. Therefore, in the present study, a eukaryotic cell expression plasmid was constructed and transfected into human $293 \mathrm{~T}$ cells by lipofection. Transient cell transfection resulted in a high level of SET oncoprotein expression, which was not regulated by natural promoters. A fluorescence marker was included in the expression cassette in order to indicate the expression and localization of the target protein in the transfected cells. SET expression in the pEGFP-N1-SET-transfected group compared with the control group was monitored by RT-qPCR and western blotting. EGFP was expressed in the pEGFP-N1- and pEGFP-N1-SET-transfected groups, but only pEGFP-N1-SET effectively exhibited SET overexpression. This result demonstrated that the target gene had been successfully transfected.

As a nuclear protein, SET has been identified to play a key role in the inhibition of normal histone acetylation and the demethylation of ectopically methylated DNA, ultimately leading to the inhibition of gene silencing and transcriptional activation (4). It has been reported that SET is overexpressed in chronic myeloid leukemia and acute myeloid leukemia, in which it is correlated with BCR/ABL expression and activity, resulting in the inhibition of $\mathrm{PP} 2 \mathrm{~A}(5,10)$. In addition, clinical data have indicated that the increasing expression of the SET gene corresponds to higher degrees of tumor malignancy (11), suggesting an oncogenic role of SET in tumorigenesis. In in vitro experiments, SET was identified to promote the progression of the cell cycle by modulating the activities of CDKs, including CDK1, CDK2 and CDK5, by interacting with the activators and/or inhibitors of the CDKs (12). In the present study, the functional activity of SET was shown to be present in the 293T cell line. The accumulation of cells in the $\mathrm{S}$ and $\mathrm{G}_{2} / \mathrm{M}$ phases was observed for the $293 \mathrm{~T}$ cells, which may be associated with the anti-apoptosis function of SET, suggesting that the overexpression of SET may exert its carcinogenesis through cell cycle arrest. Therefore, SET may be a potential target of gene therapy for leukemia and other cancers in the future.

It has been demonstrated that SET overexpression is a key contributing mechanism involved in the PP2A inhibition observed in tumors (1). Therefore, the change in PP2A level was detected in the following experiments of the present study. The relative PP2A mRNA and protein expression levels in the pEGFP-N1-SET-transfected 293T cells were downregulated compared with those in the pEGFP-N1-transfected cells. The results showed that SET mediated the decreased expression of PP2A may be of greater importance in light of the potential role of PP2A in leukemogenesis and other cancers. PP2A is a major serine/threonine phosphatase in eukaryotic cells, which consists of a $36-\mathrm{kD}$ catalytic subunit $\mathrm{C}$ (PP2Ac), a regulatory subunit A with a molecular mass of $65 \mathrm{kD}$, and a third regulatory subunit B (13). As a tumor suppressor, PP2A plays an irreplaceable role in a number of cellular processes, such as cellular metabolism, DNA replication, transcription, RNA splicing, translation, cell cycle progression and cell transformation (14). Furthermore, PP2A exhibits a positive regulatory function in apoptosis, mediating the dephosphorylation and inactivation of the anti-apoptotic Bcl-2 and activation of the pro-apoptotic factor Bad (15). As a result, PP2A has been noted as a potential therapeutic target in leukemia patients $(9,16,17)$. SET may promote the suppression of PP2A by binding directly to the catalytic subunits of PP2A and causing hyperphosphorylation of its $\tau$ unit (18). Another study has shown that SET could activate the mitogen-activated protein kinases (MAPK) kinase/extracellular signal-regulated kinases/MAPK signaling pathway, which is involved with cell spreading, motility and death receptor-elicited apoptosis. Moreover, ERK has interactions with PP2A, suggesting that cell migration may be regulated through a SET-PP2A-ERK signaling complex (19). Therefore, the overexpression of the SET oncoprotein may result in the inactivation of PP2A and thus the deactivation of PP2A target gene dephosphorylation, leading to apoptotic resistance in the tumor cells. 
Our previous study showed that $\mathrm{As}_{4} \mathrm{~S}_{4}$-induced apoptosis was associated with a reduced level of SET mRNA and protein expression in NB4-R1 cells (Wang et al, unpublished data). Therefore, the present study analyzed Bcl-2 (an anti-apoptotic protein) and Bax (a proapoptotic protein) expression in transfected $293 \mathrm{~T}$ cells in order to determine if these Bcl-2 family members played a role in $\mathrm{As}_{4} \mathrm{~S}_{4}$-induced apoptosis. The Bcl-2 expression level was increased in the pEGFP-N1-SET-transfected 293T cells compared with the expression level in the pEGFP-N1-transfected control group. Additionally, the Bcl-2 expression level was decreased in the pEGFP-N1-transfected 293T cells treated with $\mathrm{As}_{4} \mathrm{~S}_{4}$ and was further decreased in the pEGFP-N1-SET-transfected cells. Bax expression was increased slightly in the pEGFP-N1-transfected $293 \mathrm{~T}$ cells treated with $\mathrm{As}_{4} \mathrm{~S}_{4}$ and was further increased in the pEGFP-N1-SET-transfected $293 \mathrm{~T}$ cells. These results demonstrated that transfection with SET led to upregulated Bcl-2 expression and downregulated Bax expression; these changes in expression may be associated with the SET carcinogenic effect observed in previous studies $(8,9)$. The susceptibility of cells to apoptosis may be determined by the ratio between anti-apoptotic and proapoptotic members of the Bcl-2 family. The decrease in the $\mathrm{Bcl}-2 / \mathrm{Bax}$ ratio leads to the translocation of Bax from the cytoplasm to the mitochondria, promoting the release of cytochrome $\mathrm{c}$ and the activation of caspases $(20,21)$. The present results also suggested that SET has suppressive effects on apoptosis. However, further studied are required.

In conclusion, the present results showed that the SET gene could lead to the promotion of $293 \mathrm{~T}$ cell proliferation and the inhibition of PP2A expression. Overexpression of SET increased the protein expression of Bcl-2 and decreased the expression of Bax in the cells, and their susceptibility to $\mathrm{As}_{4} \mathrm{~S}_{4}$-induced apoptosis was decreased. As a key factor in carcinogenesis, this study identified SET as a critical gene in $\mathrm{As}_{4} \mathrm{~S}_{4}$-induced apoptosis and a potential novel effective therapeutic target for leukemia and other cancers. Further studies will be focused on defining the mechanism through which SET regulates PP2A levels and the role of such regulation in cell differentiation, growth and carcinogenesis.

\section{Acknowledgements}

This study was supported by the Natural Science Foundation of China (grant no. 81000218). The author would like to express gratitude to Dr. Xinyang Wang for providing access to the Oncology Research Laboratory, Key Laboratory of Environment and Genes Related to Diseases, Ministry of Education (Xi'an, China) to complete the experiment.

\section{References}

1. Cristóbal I, Garcia-Orti L, Cirauqui C, Cortes-Lavaud X, García-Sánchez MA, Calasanz MJ and Odero MD: Overexpression of SET is a recurrent event associated with poor outcome and contributes to protein phosphatase $2 \mathrm{~A}$ inhibition in acute myeloid leukemia. Haematologica 97: 543-550, 2012.
2. von Lindern M, van Baal S, Wiegant J, Raap A, Hagemeijer A and Grosveld G: Can, a putative oncogene associated with myeloid leukemogenesis, may be activated by fusion of its $3^{\prime}$ half to different genes: Characterization of the set gene. Mol Cell Biol 12: 3346-3355, 1992.

3. Li M, Guo H and Damuni Z: Purification and characterization of two potent heat-stable protein inhibitors of protein phosphatase 2A from bovine kidney. Biochemistry 34: 1988-1996, 1995.

4. Cervoni N, Detich N, Seo SB, Chakravarti D and Szyf M: The oncoprotein Set/TAF-1beta, an inhibitor of histone acetyltransferase, inhibits active demethylation of DNA, integrating DNA methylation and transcriptional silencing. J Biol Chem 277: 25026-25031, 2002.

5. Li M, Makkinje A and Damuni Z: The myeloid leukemia-associated protein SET is a potent inhibitor of protein phosphatase 2A. J Biol Chem 271: 11059-11062, 1996.

6. Jun Qi, He P, Chen W, Wang H, Wang X and Zhang M: Comparative proteome study of apoptosis induced by $\mathrm{As}_{4} \mathrm{~S}_{4}$ in retinoid acid resistant human acute promyelocytic leukemia NB4-R1 cells. Leuk Res 34: 1506-1516, 2010.

7. Livak KJ and Schmittgen TD: Analysis of relative gene expression data using real-time quantitative PCR and the 2(-Delta Delta C(T)) Method. Methods 25: 402-408, 2001

8. Lee SG, Park TS, Cho SY, Lim G, Park GJ, Oh SH, Cho EH, Chong SY and Huh JY: T-cell acute lymphoblastic leukemia associated with complex karyotype and SET-NUP214 rearrangement: A case study and review of the literature. Ann Clin Lab Sci 41: 267-272, 2011.

9. Adler HT, Nallaseth FS, Walter G and Tkachuk DC: HRX leukemic fusion proteins form a heterocomplex with the leukemia-associated protein SET and protein phosphatase $2 \mathrm{~A}$. J Biol Chem 272: 28407-28414, 1997.

10. Neviani P, Santhanam R, Trotta R, Notari M, Blaser BW, Liu S, Mao H, Chang JS, Galietta A, Uttam A, et al: The tumor suppressor PP2A is functionally inactivated in blast crisis CML through the inhibitory activity of the BCR/ABL-regulated SET protein. Cancer Cell 8: 355-368, 2005.

11. Ouellet V, Le Page C, Guyot MC, Lussier C, Tonin PN, Provencher DM and Mes-Masson AM: SET complex in serous epithelial ovarian cancer. Int J Cancer 119: 2119-2126, 2006.

12. Kumar RN, Radhakrishnan R, Ha JH and Dhanasekaran N: Proteome analysis of NIH3T3 cells transformed by activated Galpha12: Regulation of leukemia-associated protein SET. J Proteome Res 3: 1177-1183, 2004.

13. Janssens V and Goris J: Protein phosphatase 2A: A highly regulated family of serine/threonine phosphatases implicated in cell growth and signalling. J Biol Chem 353: 417-439, 2001.

14. Westermarck J and Hahn WC: Multiple pathways regulated by the tumor suppressor PP2A in transformation. Trends Mol Med 14: 152-160, 2008

15. Van Hoof $\mathrm{C}$ and Goris J: Phosphatases in apoptosis: To be or not to be, PP2A is in the heart of the question. Biochim Biophys Acta 1640: 97-104, 2003

16. Neviani P, Santhanam R, Oaks JJ,Eiring AM, Notari M,BlaserBW, Liu S, Trotta R, Muthusamy N, Gambacorti-Passerini C, et al: FTY720, a new alternative for treating blast crisis chronic myelogenous leukemia and Philadelphia chromosome-positive acute lymphocytic leukemia. J Clin Invest 117: 2408-2421, 2007.

17. Liu Q, Zhao X, Frissora F, Ma Y, Santhanam R, Jarjoura D, Lehman A, Perrotti D, Chen CS, Dalton JT, et al: FTY720 demonstrates promising preclinical activity for chronic lymphocytic leukemia and lymphoblastic leukemia/lymphoma. Blood 111: 275-284, 2008.

18. Arnaud L, Chen S, Liu F, Li B, Khatoon S, Grundke-Iqbal I and Iqbal K: Mechanism of inhibition of PP2A activity and abnormal hyperphosphorylation of tau by I2 (PP2A)/SET. FEBS Lett 585: 2653-2659, 2011.

19. Lam BD, Anthony EC and Hordijk PL: Cytoplasmic targeting of the proto-oncogene SET promotes cell spreading and migration. FEBS Lett 587: 111-119, 2013.

20. Rong Y and Distelhorst CW: Bcl-2 protein family members: Versatile regulators of calcium signaling in cell survival and apoptosis. Annu Rev Physiol 70: 73-91, 2008.

21. Martinou JC and Youle RJ: Mitochondria in apoptosis: Bcl-2 family members and mitochondrial dynamics. Dev Cell 21: 92-101, 2011. 